\title{
The Role of Religiosity in HIV Prevention in Uganda: A Case-Control Study among Muslim and Christian Youth in Wakiso District
}

\author{
Magid Kagimu ${ }^{1,2,3^{*}}$, Sarah Kaye ${ }^{1}$, Walakira Yusuf ${ }^{1}$, David Guwatudde ${ }^{3}$, Charles Rwabukwali ${ }^{4}$, \\ Dick Ainomugisha ${ }^{1}$ \\ ${ }^{1}$ Islamic Medical Association of Uganda, Kampala, Uganda; ${ }^{2}$ Department of Medicine, Makerere University College of Health Sci- \\ ences, Kampala, Uganda; ${ }^{3}$ Makerere University School of Public Health, Kampala, Uganda; ${ }^{4}$ Department of Sociology, Makerere \\ University, Kampala, Uganda. \\ Email: "mmkagimu@utlonline.co.ug
}

Received October $7^{\text {th }}, 2012$; revised November $7^{\text {th }}, 2012$; accepted November $14^{\text {th }}, 2012$

\begin{abstract}
Background: In Uganda's HIV prevention strategy religious institutions are encouraged to deliver HIV prevention messages to the general public and to integrate HIV prevention into faith-based activities such as worship, funerals and marriage ceremonies. However, there is limited data on the relationship between religiosity and HIV prevalence. Objectives: The main objective was to assess the association between religiosity, HIV-risk behaviors and HIV prevalence. Methods: A case-control study was done among Muslim and Christian youth. Cases were defined as HIV positive youth and controls were HIV negative youth. Respondents were interviewed and then tested for HIV. A religiosity index was constructed to assess the association between religiosity, HIV-risk behaviors and HIV infections. Results: Higher levels of religiosity were significantly associated with abstaining from sex, avoiding drinking alcohol and avoiding narcotics. Higher levels of religiosity were also associated with lower HIV-infections. HIV infections were significantly associated with low religiosity, having one or both parents dead, and having multiple sexual partners. Conclusions: Religiosity appears to have an important role in HIV prevention among many Ugandans. These should be encouraged and made to feel proud of using religiosity in their HIV prevention efforts. Their numbers should also be increased. Religious leaders should be energized by the study findings and they should be supported to take the lead in the efforts of using religiosity for HIV prevention. All Ugandans should use the power of God within each of them for HIV prevention in line with their motto: "For God and my country". Religiosity for HIV prevention is readily available, accessible and affordable to the majority of Ugandans. This option should be supported by all stakeholders including government, non-governmental organizations, faith-based organizations and external support agencies, by mobilizing appropriate human, technical and financial resources to accelerate its implementation.
\end{abstract}

Keywords: Religiosity; HIV Prevention; Muslim; Christian; Uganda; Youth; HIV-Risk Behaviors

\section{Introduction}

\subsection{The HIV/AIDS Situation in Uganda}

The scale of the HIV/AIDS epidemic in Uganda is still enormous and it remains of grave concern to all stakeholders. It is estimated that 1.2 million Ugandans are living with HIV/AIDS. The estimated number of newly infected individuals has continued to increase from 84,000 in 1994 to 130,000 in 2010 [1]. The overall HIV prevalence increased in the last 5 years. According to the 2004/2005 national sero-behavioral survey the overall HIV prevalence was $6.4 \%$. The HIV prevalence among the youth 15 - 24 years old was 3\% [2]. In the 2011 Uganda

\footnotetext{
"Corresponding author.
}

AIDS indicator survey the overall HIV prevalence increased to $7.3 \%$. The HIV prevalence among the youth 15 - 24 years also increased to $4 \%$ [3].

\subsection{Religiosity in Uganda's HIV Prevention Strategy}

Uganda's HIV/AIDS epidemic is predominantly heterosexually driven. Reducing heterosexual transmission of HIV is therefore, one of the priorities in Uganda's HIV prevention strategy [4]. One of the strategic actions for this is to promote ABC+. This includes Abstinence, Being faithful and Condom use in addition to other strategies that reduce sexual risk. In order to implement this, the national strategy encourages the use of all institutions 
including religious institutions to deliver HIV prevention messages and advocacy services to the general public and most at risk populations [5]. Among the youth the strategy encourages delaying the sexual debut. This can be done by incorporating appropriate messages in faithbased programs. For the community in general, the strategy encourages integration of HIV prevention into community faith-based activities such as worship, funerals and marriage ceremonies [4].

\subsection{HIV Prevalence and Religion}

According to the 2002 Ugandan census, the population of Uganda was 24.4 million. It was distributed by religious denominations as follows: Catholics $41.9 \%$; Protestants 35.9\%; Muslims 12.1\%; Pentecostals 4.6\%; Seventh Day Adventists 1.5\%; Other Christians 1.2\%; Orthodox 0.1\%; Traditional 1.0\%; Bahai 0.1\%; Other Non-Christian 0.7\% and No Religion $0.9 \%$. The majority of the Ugandans were Christians (85.2\%) and Muslims (12.1\%) forming $97.3 \%$ of the population.

In the national sero-behavioral surveys religious denominations and HIV prevalence were monitored. In the 2004/2005 sero-behavioral survey, HIV prevalence was highest among Protestants and lowest among Muslims. The HIV prevalence rates in descending order were as follows: Protestants $7.1 \%$, Catholics $6.3 \%$, other Christians $6.3 \%$, other religions 5.5\%, Muslims 5.0\% [2]. In the 2011 Uganda AIDS Indicators survey the HIV prevalence increased in all religious groups. It was highest among those with other religion or no religion and lowest among Muslims. The HIV prevalence rates in descending order were as follows: other religion or none 9.5\%, Catholics 7.8\%, Protestants 7.5\%, Seventh Day Adventists $7.5 \%$, Pentecostals $6.9 \%$, other Christians 6.4\%, and Muslims 5.7\% [3].

\subsection{Knowledge Gaps on Religiosity and HIV}

Despite the national strategy of using religious institutions in HIV prevention, there is limited data on the relationship between religiosity and HIV prevalence in Uganda. Religiosity is a difficult term to define. Many scholars define religiosity as the degree of adherence to practices and beliefs of an organized religious institution. It is a multidimensional concept involving cognitive, emotional, motivational and behavioral aspects. Some researchers argue that it is appropriate to measure overall religiosity when it is used to predict other variables while sub-dimensions can be used to predict exceptions to this rule. Whereas most researchers agree that religiosity is multidimensional there are big differences regarding the number and nature of these dimensions. Over the years global assessment of religiosity is being used less often.
Religiosity assessment is being done more by using specific scales for different dimensions [6]. There is no one word for religiosity in African languages in Uganda. The term used for religiosity is "Diini" which is borrowed from Arabic "El Din" which means "a way of life". There is limited data in Uganda on the association between "Diini” and HIV prevalence [7].

\subsection{Measurement of Religiosity Using a Composite Index}

A composite indicator is formed when individual indicators are compiled into a single index. This index should ideally measure multidimensional concepts which cannot be captured by a single indicator. The advantages of an ideal composite indicator include the following: it can summarize complex multidimensional realities with a view to support decision making, it is easier to interpret than a battery of many separate indicators, it can assess progress over time, it reduces the visible size of a set of indicators without dropping the underlying information base; and it facilitates communication with the general public.

The disadvantages of a composite index include the following: it may send misleading policy messages if poorly constructed or misinterpreted, it may invite simplistic conclusions, it may be misused to support a desired policy if the construction process is not transparent and or lacks sound statistical or conceptual principles, the selection of indicators and weights could be a source of political dispute, it may disguise serious failings in some dimensions and increase the difficulty of identifying proper remedial action if the construction process is not transparent, it may lead to inappropriate policies if dimensions of performance that are difficult to measure are ignored; and a lot of work in data collection and editing is "wasted" or hidden behind a single number of dubious significance.

In view of the above arguments it is recommended that composite indicators should only be used as a means of initiating discussion and stimulating public interest. The relevance of the composite index should be assessed in respect to those affected by it. Composite indicators are like mathematical or computational models. Their construction owes more to the craftsmanship of the modeler than to universally accepted scientific rules. The justification for a composite indicator therefore lies in its fitness for the intended purpose and in peer acceptance [8].

Scholars in religion and health discourage combining different religious variables into a single index. This is because such an index may show a weak or no relationship between it and the health outcome variable because of interactions among the variables. For example private religious activities such as prayers often increase in stressful circumstances as the individual attempts to cope 
with the difficulty. This results in a positive relationship between private prayers and depression. On the other hand Church attendance may decrease when depression increases. This results in a negative relationship between church attendance and depression. Combining private and public religious activities into a single composite index tends to cancel out the associations of each with depression. It is recommended that each religious dimension be examined separately regarding its relationship to the health outcome [9].

Attempts have been made by researchers to develop brief measures of religiosity. One such measure is the five-item Duke University Religion Index (DUREL). This measures the three major dimensions of religiosity. These dimensions are: organizational religious activity which involves public religious activities such as attending religious services, non-organizational religious activity which consists of private religious activities such as prayers and watching or listening to religious programs on radio and TV, and intrinsic religiosity which includes the degree of personal religious commitment. Even with this brief scale, the authors do not recommend summing up all three subscales into a total overall religiosity index score. The main reason for this is that combining three subscales into a single index could result in subscale scores canceling out the effects of each other. Instead they recommend examining each subscale independently regarding its relationship with health outcomes [10].

Another excellent measure of religiosity is the "Multidimensional Measurement of Religiousness/spirituality for use in health research". The authors note that religious/spiritual variables cannot simply be combined into a single variable "religiosity". Instead, each relevant dimension of religiousness and spirituality should be examined separately for its effects on physical and mental health [11].

\subsection{Study of Objectives}

The main objective of the study was to assess the association between religiosity, HIV-risk behaviors and HIV prevalence, so that more data on the role of religiosity in HIV prevention is generated for stimulating a more informed discussion of this subject.

\section{Methods}

\subsection{Study Setting}

The Islamic Medical Association of Uganda (IMAU) which is a faith-based non-governmental organization runs a hospital called "Saidina Abubakar Islamic Hospital". This hospital which is located $14 \mathrm{~km}$ north of the capital city Kampala, offers health facility medical services as well as community health services. In the com- munity religious leaders and their assistants from both Muslim and Christian faith traditions were trained by IMAU trainers to regularly educate their communities on issues of HIV prevention during sermons, home visits and group talks. It is communities surrounding SAIH that were targeted by the study.

\subsection{Study Design and Sampling}

This was a case-control study. Cases were defined as HIV positive youth 15 - 24 yrs and controls were HIV negative youth in the same age group. The youth selected to participate in the study had to be generally healthy. The sick youth were excluded. It was calculated that 100 cases and 400 controls would be needed for the Christian faith and a similar number for the Muslim faith. It was planned that Muslims and Christians were to be studied separately because of the different faith traditions. A convenience sample of 30 mosques and 30 churches surrounding SAIH participated in the study. Interviewers were trained to collect the required data from the study respondents. When they reached each place of worship they were guided by religious leaders and their assistants to surrounding homes which had 15 - 24 yrs old youth. These youth were interviewed after informed consent and blood taken from them after the interview. The interviewers did not know who was a case or a control. This was decided after data collection. Although the selection of study participants was not random, it was systematically done by moving to homes around the place of worship. At each place of worship between 50 - 100 youth were interviewed and tested for HIV. The interviewers reported that there were very few non-responses. They estimated the non-response rate to be less than $2 \%$.

\subsection{HIV Testing}

This was done using rapid HIV test kits in accordance with the Ministry of Health guidelines. The detailed methodology is reported in another publication [12].

\subsection{Religiosity Measurement}

The Brief Multidimensional Measure of Religiousness/ Spirituality formed the backbone of the religiosity measurement items [11]. It was discussed with community religious leaders and IMAU trainers. Some questions were selected from the instrument and others added to ensure the community perceptions of how religiosity should be measured were captured. There were 33 questions that were eventually used in the measurement of religiosity as shown in Table $\mathbf{1}$.

\subsection{HIV-Risk Behavior Measurement}

The questionnaire also had questions that measured HIV- 
Table 1. Religiosity dimensions measured among Muslim and Christian youth.

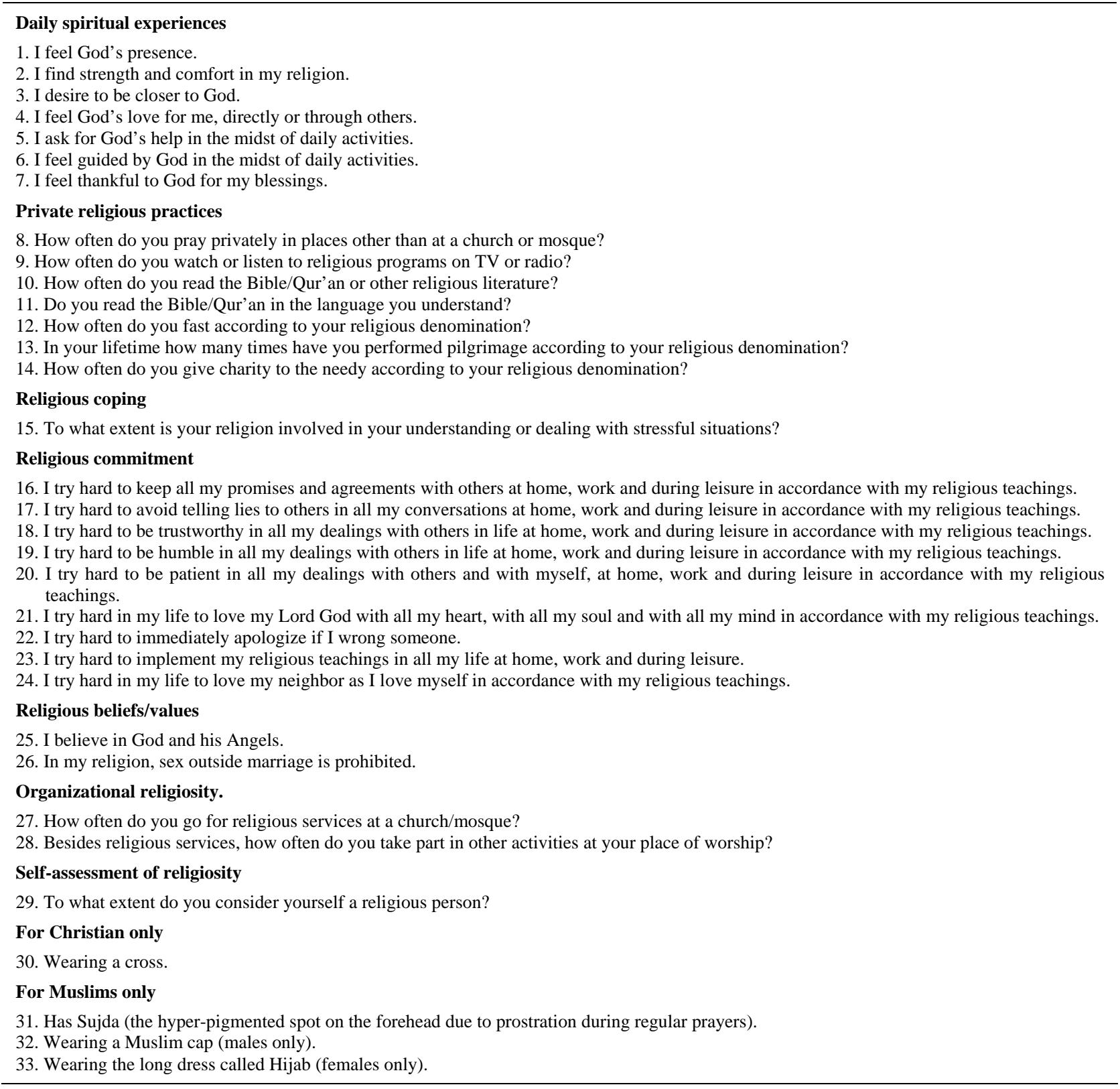

risk behaviors that were known to be driving the HIV epidemic in Uganda such as multiple sexual partners and alcohol use [13].

\subsection{Statistical Analysis}

The data were analyzed using SPSS 17.0 and Stata 10.0 statistical packages.

\subsection{Ethical Considerations}

The study was approved by Makerere University School of Public Health Institutional Review Board and the Na- tional Council of Science and Technology.

\section{Results}

\subsection{Study Respondents}

A total of 4268 respondents between 15 - 24 years were interviewed and tested for HIV from July to December 2010. These included 2933 Christians and 1224 Muslims. There were 106 HIV positive cases among Christians and 29 HIV positive cases among Muslims. The required cases were therefore obtained for Christians. The required number of cases were not achieved for Muslims 
because of their lower HIV prevalence and the lack of resources to be able to continue the search for more HIV positive Muslim youth. The controls were randomly selected from HIV negative respondents of each faith tradition. Four controls were selected for each case. This resulted in 424 controls for Christians and 116 controls for Muslims. The combined total number of cases and controls among Christians and Muslims was therefore 675 respondents, of which $52 \%$ were females. The detailed analysis of cases and controls among Christians is reported in another publication [12]. The overall HIV prevalence among Christian youth was 3.6\% and among the Muslim youth it was $2.4 \%$. The majority of the youth had primary and secondary school education. HIV infections were significantly higher among the youth who had never attended school when compared to those who had ever been to school [12].

\subsection{Validity and Reliability of the Religiosity Measurements}

Construct validity was tested using factor analysis. It was found that many questionnaire items tested the three major religiosity dimensions of daily spiritual experiences, religious commitment and religious practices both private and organizational. The details are shown in Table 2.

The internal consistency reliability was tested among all cases and controls using the Cronbach's alpha and it was found to be adequate at 0.84 . The test retest reliability was done after one week on a sample of 37 Christians and 22 Muslims and the intra-class correlation coeffi- cients were found to be adequate, being above 0.7

\subsection{Religiosity Index Construction}

All the 33 religiosity items were first examined regarding how they relate together using Cronbach's alpha. This was to assess if the newly created index was internally consistent. As a rule of thumb Cronbach's alpha should be above 0.70 for one to be confident that the items being combined in a single index are related enough to warrant their combination into a single scale. The Cronbach's alpha was above 0.70 . Correlations less than 0.30 were removed from the scale. The final scale had 11 items for creating the index as shown in Table 3.

The variables were recoded so that "high" numeric values indicated a strongly positive experience or practice. An index variable was then created summing up the scores. The minimum index score was 31 and the maximum score 74 . The scores were re-categorized as follows: Low religiosity: score $=31-45$; moderate religiosity: score $=46-60$; and High religiosity: score $=61-74$. These categories were used to assess the association between religiosity and other variables.

\subsection{Association between Religiosity, HIV-Risk Behaviors and HIV}

In this analysis Muslims and Christians were combined to increase the numbers available for statistical analysis. As shown in Table 4, higher levels of religiosity were significantly associated with abstaining from sex, avoiding

Table 2. Religiosity measurement items correlated with the $\mathbf{3}$ major factors in a rotated component matrix.

\begin{tabular}{|c|c|c|c|}
\hline & $\begin{array}{c}\text { Factor } 1 \\
(\text { Eigenvalue }=5.439)\end{array}$ & $\begin{array}{c}\text { Factor } 2 \\
(\text { Eigenvalue }=2.858)\end{array}$ & $\begin{array}{c}\text { Factor } 3 \\
(\text { Eigenvalue }=2.559)\end{array}$ \\
\hline \multicolumn{4}{|l|}{ Daily spiritual experiences } \\
\hline I feel God's presence. & & 0.779 & \\
\hline I find strength and comfort in my religion. & & 0.775 & \\
\hline I desire to be closer to God. & & 0.724 & \\
\hline I feel God's love for me directly or through others. & & 0.442 & \\
\hline I ask for God's help amidst daily activities. & & 0.389 & \\
\hline \multicolumn{4}{|l|}{ Religious commitment } \\
\hline I try hard to keep promises. & 0.706 & & \\
\hline I try hard to avoid telling lies. & 0.639 & & \\
\hline I try hard to be trustworthy. & 0.787 & & \\
\hline I try hard to be humble. & 0.818 & & \\
\hline I try hard to be patient. & 0.796 & & \\
\hline I try hard to love God. & 0.453 & & \\
\hline I try hard to implement my religious teachings in life. & 0.387 & & \\
\hline How often do you pray privately. & & & 0.597 \\
\hline How often do you listen to or watch TV/radio religious programs. & & & 0.492 \\
\hline How often do you fast. & & & 0.523 \\
\hline How often do you give charity. & & & 0.655 \\
\hline How often do you go for church/mosque services. & & & 0.581 \\
\hline How often do you take part in other church/mosque activities. & & & 0.366 \\
\hline
\end{tabular}

Valid respondents 4162. There were 10 factors with Eigenvalues above 1 as follows: there were 3 factors with Eigenvalues above 2: factors 1 , 2 and 3; there were 7 factors with Eigenvalues below 2: factors 4 - 10, Eigenvalues range: 1.021 - 1.464. 
Table 3. Items included in religiosity index.

\begin{tabular}{lc}
\hline \multicolumn{1}{c}{ Item } & Corrected item total correlation \\
\hline Daily spiritual experiences & 0.369 \\
1. I feel God's presence. & 0.395 \\
2. I find strength and comfort in my religion. & 0.414 \\
3. I desire to be closer to God. & 0.318 \\
4. I feel God's love for me directly or through others. & 0.347 \\
5. I ask for God's help in the midst of daily activities. & 0.386 \\
6. I feel guided by God in the midst of daily activities. & 0.362 \\
Private religious practices & 0.333 \\
7. How often do you pray privately other than at a church or mosque? & 0.389 \\
8. How often do you watch or listen to religious programs on TV or radio? & 0.435 \\
9. How often do you read the Bible/Qur'an or other religious literature? & 0.381 \\
10. Do you read the Bible/Qur'an in the language you understand? & \\
Organizational religiosity & \\
11. How often do you go for a religious service at a church or mosque? & \\
\hline
\end{tabular}

Valid number of respondents 596 out of $675=88.3 \%$. Scores: minimum 31, maximum 74 .

Table 4. Association between religiosity, HIV-risk behaviors and HIV infections on bivariate analysis of combined Muslim and Christian youth.

\begin{tabular}{|c|c|c|c|c|}
\hline \multirow{2}{*}{ Characteristic } & High religiosity & Moderate religiosity & Low religiosity & p-value \\
\hline & n (\%) & n (\%) & n (\%) & \\
\hline $\begin{array}{l}\text { Ever had sex } \\
\text { No (abstaining = A) } \\
\text { Yes }\end{array}$ & $\begin{array}{c}94(28) \\
240(72)\end{array}$ & $\begin{array}{c}34(14) \\
210(86)\end{array}$ & $\begin{array}{c}1(6) \\
17(94)\end{array}$ & $<0.001$ \\
\hline $\begin{array}{l}\text { Sex outside marriage } \\
\text { No (being faithful = B) } \\
\text { Yes }\end{array}$ & $\begin{array}{l}62(50) \\
61(50)\end{array}$ & $\begin{array}{l}48(49) \\
49(51)\end{array}$ & $\begin{array}{l}3(33) \\
6(67)\end{array}$ & 0.613 \\
\hline $\begin{array}{l}\text { Ever used condoms } \\
\text { Yes }(\text { condom use = C) } \\
\text { No }\end{array}$ & $\begin{array}{l}40(66) \\
21(34)\end{array}$ & $\begin{array}{l}30(56) \\
24(44)\end{array}$ & $\begin{array}{l}4(67) \\
2(33)\end{array}$ & 0.524 \\
\hline $\begin{array}{l}\text { Sexual partners } \\
\text { One } \\
\text { Multiple }\end{array}$ & $\begin{array}{c}40(18) \\
187(82)\end{array}$ & $\begin{array}{c}34(17) \\
168(83)\end{array}$ & $\begin{array}{c}1(6) \\
16(94)\end{array}$ & 0.459 \\
\hline $\begin{array}{l}\text { Ever drank alcohol } \\
\text { No } \\
\text { Yes }\end{array}$ & $\begin{array}{l}192(58) \\
140(42)\end{array}$ & $\begin{array}{c}98(40) \\
145(60)\end{array}$ & $\begin{array}{c}6(33) \\
12(67)\end{array}$ & $<0.001$ \\
\hline $\begin{array}{l}\text { HIV status } \\
\text { Negative (controls) } \\
\text { Positive (cases) }\end{array}$ & $\begin{array}{c}282(84) \\
52(16)\end{array}$ & $\begin{array}{c}183(75) \\
61(25)\end{array}$ & $\begin{array}{c}15(83) \\
3(17)\end{array}$ & 0.017 \\
\hline $\begin{array}{l}\text { Ever used narcotics } \\
\text { Yes } \\
\text { No }\end{array}$ & $\begin{array}{c}9(3) \\
322(97)\end{array}$ & $\begin{array}{c}22(9) \\
218(91)\end{array}$ & $\begin{array}{c}1(6) \\
17(94)\end{array}$ & 0.004 \\
\hline
\end{tabular}

drinking alcohol and avoiding narcotics for recreation when compared with lower levels. Higher levels of religiosity were also associated with lower HIV infection rates when compared with lower levels.

\subsection{Logistic Regression Models for Associations between Religiosity, HIV-Risk Behaviors, and HIV Infections}

The logistic regression models with significant associations between religiosity, HIV-risk characteristics and HIV infections are shown in Table 5. Lack of abstaining from sex was associated with low religiosity, being male and being a young adult. Drinking alcohol was associated with low religiosity, being a young adult and being a Christian as compared to being a Muslim. HIV infections were associated with low religiosity, having one or both parents dead and having multiple sexual partners.

\section{Discussion}

In this study higher levels of religiosity were associated with avoiding HIV-risk behaviors such as sexual activity, alcohol use and narcotic drug use among the youth. This 
Table 5. Logistic regression models with significant associations between religiosity, HIV-risk characteristics and HIV infections.

\begin{tabular}{lcc}
\hline & Odds ratio & 95\% CI \\
\hline Ever had sex (not abstaining) & & $1.68-4.43$ \\
Low religiosity & 2.72 & $1.04-2.80$ \\
Male gender & 1.70 & $12.53-35.81$ \\
Young adult (20 - 24 yrs) & 21.19 & $1.29-2.47$ \\
Ever drank alcohol & & $2.29-5.01$ \\
Low religiosity & 1.78 & $2.91-7.82$ \\
Young adult & 3.39 & $<0.001$ \\
Christian & 4.77 & $<0.001$ \\
HIV positive & & $<0.001$ \\
Low religiosity & $1.54-2.27$ \\
One or both parents dead & 1.60 & $1.17-2.18$ \\
Multiple sexual partners & 3.91 & $1.64-9.36$ \\
\hline
\end{tabular}

Hosmer-Lemeshow goodness of fit tests: Ever had sex: p = 0.804; Ever drank alcohol: $p=0.793$, HIV positive: $p=0.102$.

is consistent with what other scholars have observed. For example it has been noted that girls who remain virgins throughout adolescence cite religious reasons for their sexual abstinence more often than any other reasons [14].

Lower levels of religiosity were associated with higher HIV infection rates among the youth studied. The drivers of the epidemic among these youth included low religiosity, having lost one or both parents and having multiple sexual partners. All these factors may act independently to drive the epidemic as shown in the logistic regression model.

This study has a limitation in that not all dimensions of religiosity were included in the index. The interpretation of the findings must therefore, be related to the items in the index. Nevertheless the study highlights the role of these measures of religiosity in HIV prevention. Another limitation of the study was that the responses to the items on religiosity were self-reported and some respondents could have given socially desirable answers. However, this effect is likely to have been limited because the findings such as those regarding the relationship between abstinence from sex and religiosity were consistent with what has been documented. One other limitation is that it was not possible to determine what came first whether religiosity or HIV infections. However, because HIV infections in the 15 - 24 years age-group are relatively new and religiosity values for the youth are usually acquired from parents in childhood, it is possible that religiosity came first before HIV infections.

\section{Conclusions}

In conclusion, higher levels of religiosity were associated with several low HIV-risk behaviors and lower HIV infection rates among the Ugandan youth studied. Religiosity therefore appears to have an important role in HIV prevention among Ugandans. Many Ugandans are likely to be using religiosity for HIV prevention in their daily lives. These should be encouraged and supported to continue using it. Steps should be taken by all stakeholders to increase the number of such people who use religiosity for HIV prevention. These people should be made to feel proud of using religiosity in their HIV prevention efforts.

Religious leaders should be energized by the study findings showing the wisdom of faith teachings and their role in HIV prevention. They should lead the efforts of using religiosity for HIV prevention and they should be supported in this by all stakeholders including governments, external support agencies, non-governmental organizations, faith-based organizations and the communities. Religiosity should be included among the strategic actions for HIV prevention and appropriate financial, human and technical resources mobilized to promote this option, by the stakeholders. This HIV prevention option is more readily available, accessible, acceptable and affordable to the majority of Ugandans in comparison to the biomedical interventions.

More research is needed to increase understanding of how religiosity works to reduce new HIV infections. The power of God the unseen needs to be studied more and utilized more efficiently and effectively to reduce new HIV infections so that eventually the HIV prevalence is reduced. It is similar to studying and utilizing other unseen forces such as gravity and electricity. All Ugandans should strive to use the power of God within each of them for HIV prevention in line with their motto "For God and my country”. A similar approach may be used by all people of faith wherever they may be, who face similar challenges.

\section{Acknowledgements}

We are grateful to Makerere University School of Public Health CDC HIV/AIDS Fellowship program and the 
Federation of Islamic Medical Associations (FIMA) for their support in this work.

\section{REFERENCES}

[1] Uganda AIDS Commission, "National HIV/AIDS Strategic Plan 2011/12-2014/15,” Uganda AIDS Commission, Kampala, 2011.

[2] Ministry of Health (MOH) [Uganda] and ORC MACRO, "Uganda HIV/AIDS Sero-behavioral Survey 2004-2005," Ministry of Health and ORC Macro, Calverton, 2006.

[3] Ministry of Health (MOH) [Uganda], "Uganda AIDS Indicator Survey 2011,” Ministry of Health, 2012.

[4] Uganda AIDS Commission, "National HIV Prevention Strategy 2011-2015”, Uganda AIDS Commission, Kampala, 2011.

[5] Uganda AIDS Commission, "Moving towards Universal Access: National HIV/AIDS Strategic Plan 2007/82011/12,” Uganda AIDS Commission, Kampala, 2007.

[6] P. Paraschiva and M. Nicoleta, "Ways of Approaching Religiosity in Psychological Research," The Journal of International Social Research, Vol. 4, No. 18, 2011, pp. 352-362.

[7] A. B. T. Byaruhanga-Akiiki, "African World Religion. A Grassroots Perspective,” Makerere University, Kampala, 1995.

[8] Organization for Economic Co-Operation and Develop- ment (OECD), "Handbook on Construction of Composite Indicators: Methodology and User Guide,” OECD, 2008.

[9] H. G. Koenig, M. E. McCullough and D. B. Larson, "Handbook of Religion and Health," Oxford University Press, Oxford, 2001. doi:10.1093/acprof:oso/9780195118667.001.0001

[10] H. G. Koenig and A. Bussing, “The Duke University Religion Index (DUREL): A Five-Item Measure for Use in Epidemiological Studies,” Religions, Vol. 1, No. 1, 2010, pp. 78-85. doi:10.3390/rel1010078

[11] Fetzer Institute/National Institute of Aging Working Group, "Multidimensional Measurement of Religiousness/Spirituality for Use in Health Research: A Report of the Fetzer Institute/National Institute on Aging Working Group,” John E. Fetzer Institute, Kalamazoo, 1999.

[12] M. Kagimu, D. Guwatudde, C. Rwabukwali, S. Kaye, Y. Walakira and D. Ainomugisha, "Religiosity for HIV Prevention in Uganda: A Case Study among Christian Youth in Wakiso District," African Health Sciences, Vol. 12, No. 1, 2012, pp. 17-25.

[13] Uganda AIDS Commission, "Uganda HIV Prevention Response and Modes of Transmission Analysis,” Uganda AIDS Commission, Kampala, 2009.

[14] A. Adamczyk, "Investigating the Role of Religion-Supported Secular Programs for Explaining Initiation into First Sex," Journal for the Scientific Study of Religion, Vol. 51, No. 2, 2012, pp. 324-342. doi:10.1111/j.1468-5906.2012.01644.x 